\title{
Lifecourse predictors of adult respiratory function: results from the Newcastle Thousand Families Study
}

\author{
P W G Tennant, ${ }^{1}$ G John Gibson, ${ }^{1,2}$ M S Pearce ${ }^{1,3}$
}

${ }^{1}$ School of Clinical Medical Sciences, Newcastle University, Newcastle upon Tyne, UK; ${ }^{2}$ Department of Respiratory Medicine, Freeman Hospital, Newcastle upon Tyne, UK;

${ }^{3}$ Institute of Health and Society, Newcastle University,

Newcastle upon Tyne, UK

Correspondence to: Dr M S Pearce, Sir James Spence Institute, Newcastle University, Royal Victoria Infirmary, Newcastle upon Tyne NE1 4LP, UK;

m.s.pearce@ncl.ac.uk

Received 22 January 2008 Accepted 19 March 2008 Published Online First 11 April 2008

\section{ABSTRACT}

Background: Impaired development in utero is suggested to increase the risk of poor respiratory health in adulthood, although a consensus has not been reached. A possible explanation for discrepancies between previous studies is inconsistent controlling for potential confounding factors, particularly childhood infections. Also, little is known regarding the relative importance of factors operating at different stages of the lifecourse. We have used detailed longitudinal data from the Newcastle Thousand Families cohort to assess the impact of birth weight, and various other factors acting throughout the lifecourse, on predicting forced expiratory volume in $1 \mathrm{~s}$ $\left(\mathrm{FEV}_{1}\right)$.

Methods: Detailed information was collected prospectively during childhood, including birth weight, childhood infections and socioeconomic circumstances. At age 4951 years, 412 study members attended for clinical examination and measurement of $\mathrm{FEV}_{1}$. These data were analysed in relation to a range of factors from across the lifecourse using linear regression models.

Results: After adjustment for all other significant variables, increasing birth weight, standardised for sex and gestational age $(p=0.011)$, being breast fed for more than 4 weeks $(p=0.017)$, less frequent childhood lower respiratory tract infections (LRTI) ( $p=0.015)$, nonsmoking $(p<0.001)$, lower body fat percentage $(p=0.010)$, male sex $(p<0.001)$, no history of asthma $(p=0.013)$ and greater adult height $(p<0.001)$ were all independently associated with higher adult $\mathrm{FEV}_{1}$.

Conclusion: Adult lung function is influenced by numerous factors during an individual's lifetime, acting both directly and indirectly throughout the lifecourse. As expected, sex, height and smoking were the most important predictors of $\mathrm{FEV}_{1}$, but birth weight, breast feeding and childhood LRTIs also contributed significantly.

The fetal programming hypothesis proposes that impaired development in utero increases the risk of adverse health in adulthood. ${ }^{1}$ A number of previous epidemiological studies have examined this hypothesis in the context of respiratory health. Although most identified that lower birth weight was associated with lower adult forced expiratory volume in $1 \mathrm{~s}\left(\mathrm{FEV}_{1}\right)$, some found no evidence of such a relationship. ${ }^{2}$

One potential reason for these conflicting results is the difficulty of determining the additional influence of lower respiratory tract infections (LRTIs) in early childhood, the risk of which may itself be partly determined by size at birth and gestational age, in addition to other factors, such as social class in early childhood. This presents a particular problem in studies where details of early infections have not been collected prospectively during childhood. Childhood LRTIs have been previously shown to predict reduced lung function in later life. ${ }^{3-8}$ These infections may lie on the causal pathway between fetal growth and adult respiratory health. In addition, factors such as gestational age and sex have not always been taken into account. ${ }^{9}$ Gestational age is especially important for lung function as preterm infants have the added complication of immature lungs.

The effects of other factors on respiratory health, such as infant feeding and social class in childhood, as well as smoking, social class and occupational exposures to dust and fumes in adulthood, also need to be taken into account, in order to assess the relative magnitude of factors operating at different stages of life. The Newcastle Thousand Families cohort, consisting of all 1142 infants born in May and June 1947 to mothers residing within the city of Newcastle upon Tyne (northern England), provides a unique opportunity to apply a lifecourse approach to adult respiratory function. Two-thirds of these children were followed until the age of 15 years, with detailed information collected prospectively on their health, growth and socioeconomic circumstances, ${ }^{10}$ and all available individuals were reassessed at age 4951 years. We used data collected prospectively at birth, during childhood and at age 49-51 years to identify significant predictors of $\mathrm{FEV}_{1}$ with the aim of establishing the relative importance of risk factors acting throughout the lifecourse.

\section{METHODS}

Participants in the current investigation were members of the cohort who were either traced through the National Health Service Central Register or contacted the study team in response to media publicity in the mid 1990s. Data on fetal and infant life and childhood had been collected prospectively. Between October 1996 and December 1998, questionnaires on health and lifestyle were completed and study members attended for clinical examination. ${ }^{10-12}$ Ethics approval for the study was obtained from the appropriate local research ethics committees and all participants gave their written informed consent.

\section{Clinical assessment}

$\mathrm{FEV}_{1}$ was measured using a portable spirometer (Vitalograph Compact II, Vitalograph, Buckingham, UK) by one of two trained research nurses. The highest value from a minimum of three attempts was recorded for each individual. An interobserver error of $1.4 \%$ and an intraobserver error of $2.2 \%$ were observed. Exhaled carbon 
Table 1 Descriptive statistics for continuous variables

\begin{tabular}{|c|c|c|c|c|c|c|c|}
\hline \multirow[b]{2}{*}{ Time point } & \multirow[b]{2}{*}{ Variable (normally distributed) } & \multicolumn{2}{|c|}{ Men $(n=169)$} & \multirow[b]{2}{*}{ n } & \multicolumn{2}{|c|}{ Women $(n=223)$} & \multirow[b]{2}{*}{$\mathbf{n}$} \\
\hline & & Range & Mean (SD) & & Range & Mean (SD) & \\
\hline Fetal & Birth weight* (z score) & $-2.7-2.2$ & $-0.3(0.9)$ & 169 & $-3.2-3.0$ & $0.0(1.1)$ & 223 \\
\hline General & Height $(\mathrm{cm})$ & 151.4-189.7 & $173.3(6.5)$ & 168 & $147.1-176.1$ & $161.4(6.0)$ & 221 \\
\hline Time point & Variable (not normally distributed) & Range & Median (IOR) & n & Range & Median (IOR) & $\mathbf{n}$ \\
\hline Childhood & Total colds between ages 0 and 5 & $0-13$ & $3(2-5)$ & 168 & $0-12$ & $3(1-5)$ & 222 \\
\hline Adulthood & Cigarette smoking history (pack-years) $\dagger$ & $0.1-73.0$ & $22.6(8.3-33.5)$ & 110 & $0.1-40.5$ & $17.2(5.7-26.0)$ & 120 \\
\hline Outcome & $\mathrm{FEV}_{1}$ (I) & $1.6-5.6$ & $3.6(3.2-3.9)$ & 169 & $1.4-4.7$ & $2.6(2.3-2.9)$ & 223 \\
\hline
\end{tabular}

${ }^{*}$ Adjusted for sex and gestational age. ${ }^{13}$

$\uparrow$ Excluding 56 men and 103 women who had never smoked.

$\mathrm{FEV}_{1}$, forced expiratory volume in $1 \mathrm{~s}$; LRTls, lower respiratory tract infections; URTIs, upper respiratory tract infections, excluding colds.

monoxide was measured using a carbon monoxide monitor (Smokerlyzer; Bedfont Scientific, Rochester, Kent, UK). Height and weight were recorded and per cent body fat was estimated from bioelectrical impedance measured using a Holtain body composition analyser (Holtain Ltd, Crymych, Wales, UK).

\section{Measurement of early life experience}

Information on a number of factors, including birth weight, gestational age, infant feeding, social class and housing conditions were recorded prospectively for all study members. Birth weights, as recorded by the midwife, were standardised for gestational age and sex. ${ }^{13}$ Social class was defined according to the UK Registrar General's Standard Occupation Classification (I (assumed to be the most advantaged), II, III non-manual, III manual, IV and V (assumed to be the least advantaged)) using paternal occupation at birth. Housing conditions were assessed by the city's Public Health Department, and scored for the presence of overcrowding, lack of hot water, toilets shared between households and dampness or poor repair. Over the following 15 years, episodes of illness were reported to the study team by health visitors who visited the families regularly throughout childhood, and general practitioners if a child presented to them with an illness. The study team was also informed whenever the children were referred to, or attended, hospital. To minimise attrition, only illness records from the first 5 years are used in this study. Measles, whooping cough, tuberculosis and influenza were coded as dichotomous variables ("ever had", "never had") while the number of episodes of LRTIs (defined as episodes of bronchitis, pneumonia or other non-specific chest infections), colds and other upper respiratory tract infections (URTIs) were recorded as counts. URTIs, other than colds, were defined as episodes of laryngitis, pharyngitis, sinusitis, tonsillitis, tracheitis or other non-specific infections affecting the throat or trachea.

\section{Measurement of adult socioeconomic position and lifestyle}

Data on adult health and lifestyle were collected by selfcompletion questionnaire at age 49-51 years. Current alcohol consumption was divided into four categories, based on average number of units consumed per week. Light drinking was defined as less than 5 units of alcohol per week for women (and 10 for men) and moderate drinking as up to 21 units for women (and 28 for men). Current physical activity assessment was based on the Medical Research Council's national survey of health and development, ${ }^{14}$ although the lowest category was partitioned to differentiate between low activity and zero activity individuals.
Occupational details of the main wage earner in the household at age 49-51 years were coded according to the 1990 UK Registrar General's Standard Occupational Classification and hence current social class was derived.

The number of pack-years of cigarettes smoked (1 pack-year equals one pack of 20 cigarettes smoked per day for 1 year) was estimated from the study members' smoking habits at ages 15 , 25, 35 and 50 years, as recorded on the self-completion questionnaire at age 49-51 years. A variable for current smoking status (never, ex-smoker and current smoker) was also derived. We have previously shown that less than $2 \%$ of reported nonsmokers had an exhaled carbon monoxide level of greater than 10 ppm. ${ }^{15}$ Occupational exposure to asbestos, dust or fumes was estimated by use of a job exposure matrix. ${ }^{16}$ Individuals were placed into two groups, "normal" and "increased", according to their likelihood of exposure, where "increased" included anyone who had ever been employed in an occupation with a "high" likelihood of exposure for "most" employees (according to the job exposure matrix). Use of $\beta$ blockers was estimated from selfreported current medication. Study members were also asked to report if they had ever been diagnosed with asthma, or if they had recently suffered from a LRTI. Self-reported history of asthma was combined with any recorded childhood diagnoses, to maximise detection.

\section{Statistical analysis}

Twins $(n=11)$ were excluded from all analyses. How representative the participants in this study were, in relation to the original cohort, was examined using a combination of $t$, MannWhitney and $\chi^{2}$ tests, according to the characteristics of the data.

Social class at birth and in adulthood, housing conditions at birth, current smoking status, physical activity and alcohol consumption were all treated as categorical variables. Relationships between $\mathrm{FEV}_{1}$ and potential explanatory variables were estimated by linear regression. Unadjusted coefficients for each variable were determined to estimate the total influence of that variable on $\mathrm{FEV}_{1}$. To estimate the direct influence of each variable (ie, not mediated through other factors), an adjusted model was constructed using backwards stepwise regression. Height was included in the model as a quadratic term $\left(b_{1}\right.$ height $+b_{2}$ height squared) because of a non-linear relationship with $\mathrm{FEV}_{1}$ (height squared was transformed to have a mean of 0 , to prevent colinearity with height). The presence of heteroskedasticity was determined using the Cook-Weisberg test. Where necessary, Huber/White estimators of variance were used to 
Table 2 Descriptive statistics for categorical variables

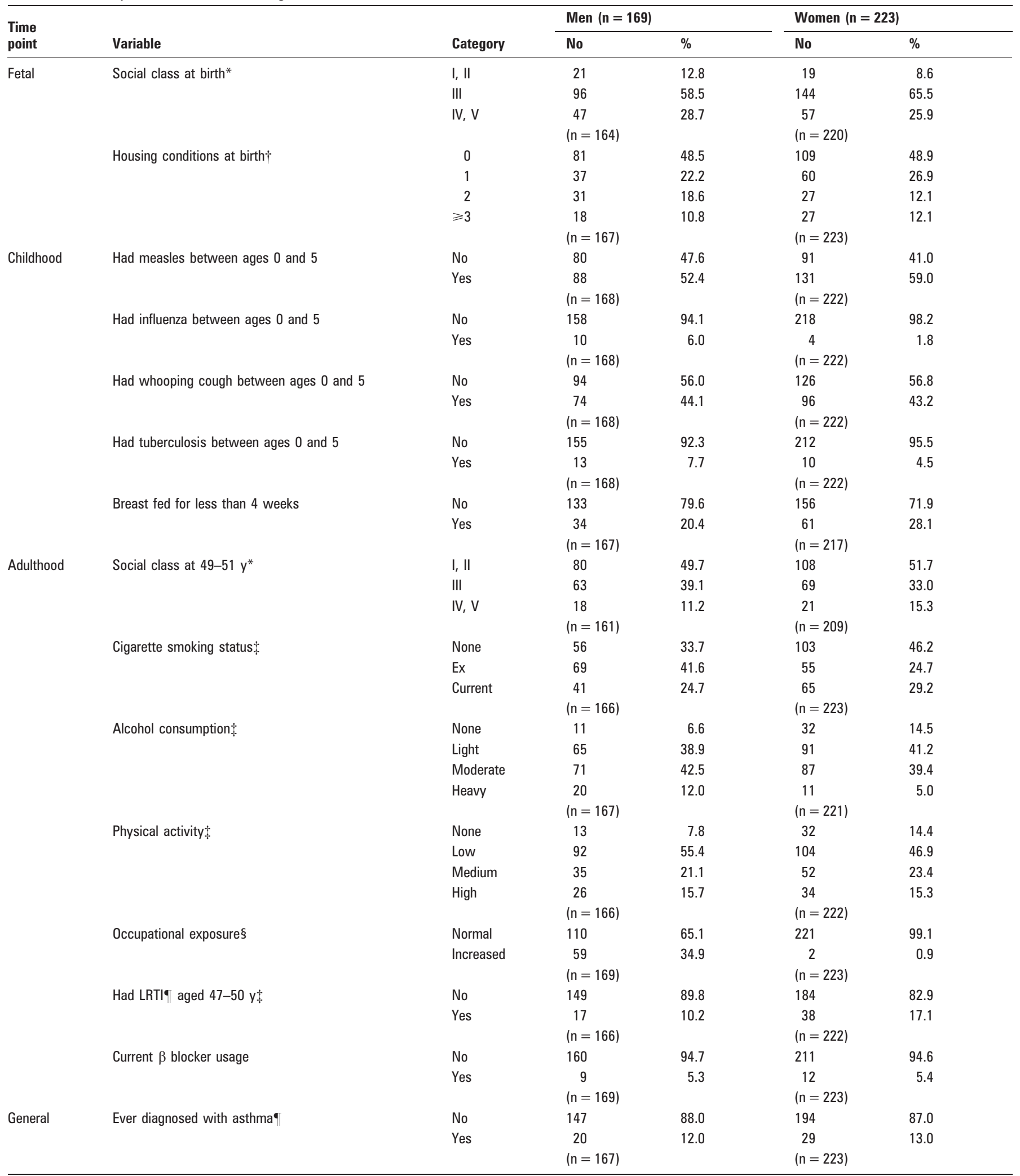

${ }^{*}$ As defined by the UK Registrar General's Standard Occupational Classification, where I is the most advantaged and V the least.

FFrom 0 to 3 or more of: overcrowding, lack of hot water, shared toilet and dampness or poor repair.

$\$$ Self-reported.

$\S$ Ever employed in an occupation with an increased risk of exposure to asbestos, dust or fumes. ${ }^{16}$

- Self-reported or abstracted from early records.

LRTI, lower respiratory tract infection. 
Table 3 Results of regression analysis showing the coefficients for all variables on FEV

\begin{tabular}{|c|c|c|c|c|c|c|c|c|}
\hline $\begin{array}{l}\text { Time } \\
\text { point }\end{array}$ & Variable & Category & $\begin{array}{l}\text { Unadjusted coefficient } \\
(95 \% \mathrm{Cl})\end{array}$ & p Value & & $\begin{array}{l}\text { Adjusted coefficient } \\
\text { (95\% CI) }\end{array}$ & p Value & \\
\hline \multirow[t]{5}{*}{ Fetal } & \multirow[t]{3}{*}{ Social class at birth* } & I, II & Reference & & \multirow[t]{3}{*}{$\begin{array}{l}\text { Total for } \\
\text { variable: } \\
0.096\end{array}$} & & & \\
\hline & & III & $-0.222(-0.470$ to 0.025$)$ & 0.078 & & & & \\
\hline & & IV, V & $-0.296(-0.565$ to -0.027$)$ & 0.031 & & & & \\
\hline & Housing conditions at birth $\dagger$ & 0 & Reference & & \multirow{2}{*}{$\begin{array}{l}\text { Total for } \\
\text { variable: } \\
0.506\end{array}$} & & & \\
\hline & Standardised birth weight + (z score) & & $0.047(-0.024$ to 0.118$)$ & 0.191 & & $0.067(0.016$ to 0.119$)$ & 0.011 & \\
\hline \multirow[t]{10}{*}{ Childhood } & \multirow[t]{2}{*}{ Had measles between ages 0 and 5} & No & Reference & 0.090 & & & & \\
\hline & & Yes & $-0.129(-0.278$ to 0.020$)$ & & & & & \\
\hline & Had influenza between ages 0 and 5 & No & Reference & & & & & \\
\hline & \multirow{2}{*}{$\begin{array}{l}\text { Had tuberculosis between ages } 0 \text { and } \\
5\end{array}$} & No & Reference & & & & & \\
\hline & & Yes & $0.004(-0.311$ to 0.319$)$ & 0.979 & & & & \\
\hline & \multirow{2}{*}{ Breast fed for less than 4 weeks } & No & Reference & & & Reference & & \\
\hline & & Yes & $-0.245(-0.416$ to -0.074$)$ & 0.005 & & $-0.148(-0.269$ to -0.027$)$ & 0.017 & \\
\hline & Total colds during ages 0 and 5 & & $0.013(-0.014$ to 0.041$)$ & 0.347 & & & & \\
\hline & Total URTIs during ages 0 and 5 & & $-0.026(-0.064$ to 0.012$)$ & 0.183 & & & & \\
\hline & Total LRTIs during ages 0 and 5 & & $-0.072(-0.133$ to -0.011$)$ & 0.021 & & $-0.049(-0.088$ to -0.009$)$ & 0.015 & \\
\hline \multirow[t]{15}{*}{ Adulthood } & \multirow[t]{3}{*}{ Social class at $49-51^{*}$} & I, II & Reference & & & & & \\
\hline & & III & $-0.124(-0.287$ to 0.039$)$ & 0.135 & \multirow{2}{*}{$\begin{array}{l}\text { Total for } \\
\text { variable: } \\
0.168\end{array}$} & & & \\
\hline & & IV, V & $-0.178(-0.407$ to 0.050$)$ & 0.125 & & & & \\
\hline & \multirow[t]{4}{*}{ Physical activity§ } & None & Reference & & \multirow{4}{*}{$\begin{array}{l}\text { Total for } \\
\text { variable: } \\
0.004\end{array}$} & & & \\
\hline & & Low & $0.388(0.152$ to 0.624$)$ & 0.001 & & & & \\
\hline & & Medium & $0.447(0.185$ to 0.709$)$ & 0.001 & & & & \\
\hline & & High & $0.438(0.157$ to 0.719$)$ & 0.002 & & & & \\
\hline & \multirow[t]{2}{*}{ Occupational exposure } & Normal & Reference & & & & & \\
\hline & & Increased & $0.698(0.506$ to 0.890$)$ & $<0.001$ & & & & \\
\hline & Had LRTI during last 3 years§ & No & Reference & & & & & \\
\hline & & Yes & $-0.301(-0.513$ to -0.089$)$ & 0.005 & & & & \\
\hline & Current $\beta$ blocker usage & No & Reference & & & & & \\
\hline & & Yes & $-0.178(-0.506$ to 0.150$)$ & 0.287 & & & & \\
\hline & Cigarette smoking history (pack-years) & & $-0.002(-0.007$ to 0.003$)$ & 0.515 & & & & \\
\hline & Body fat $(\%)$ & & $-0.025(-0.033$ to -0.017$)$ & $<0.001$ & & $-0.008(-0.014$ to -0.002$)$ & 0.010 & \\
\hline General & Sex & Male & Reference & & & Reference & & \\
\hline & & Female & $-0.951(-1.071$ to -0.830$)$ & $<0.001$ & & $-0.609(-0.763$ to -0.455$)$ & $<0.001$ & \\
\hline & Ever diagnosed with asthma** & No & Reference & & & Reference & & \\
\hline & & Yes & $-0.313(-0.534$ to -0.091$)$ & 0.006 & & $-0.199(-0.356$ to -0.041$)$ & 0.013 & \\
\hline
\end{tabular}


Table 3 Continued

\begin{tabular}{|c|c|c|c|c|c|c|}
\hline $\begin{array}{l}\text { Time } \\
\text { point }\end{array}$ & Variable & Category & $\begin{array}{l}\text { Unadjusted coefficient } \\
(95 \% \mathrm{Cl})\end{array}$ & p Value & $\begin{array}{l}\text { Adjusted coefficient } \\
(95 \% \mathrm{CI})\end{array}$ & p Value \\
\hline & Height $(\mathrm{cm})$ & & $0.054(0.047$ to 0.061$)$ & $<0.001$ & $0.022(0.012$ to 0.032$)$ & $<0.001$ \\
\hline & $\begin{array}{l}\text { Height }{ }^{2}\left(\mathrm{~cm}^{2} \times 10^{3}\right) \text { (difference from } \\
\text { mean) }\end{array}$ & & $1.321(0.332$ to 2.310$)$ & 0.009 & $0.758(0.026$ to 1.491$)$ & 0.043 \\
\hline
\end{tabular}

Adjusted coefficients are shown for variables included in the adjusted model.

${ }^{*}$ As defined by the UK Registrar General's Standard Occupational Classification, where I is the most advantaged.

†From 0 to 3 or more of: overcrowding, lack of hot water, shared toilet and dampness or poor repair.

¥Adjusted for sex and gestational age. ${ }^{13}$

$\S$ Self reported.

- Ever employed in an occupation with an increased risk of exposure to asbestos, dust or fumes. ${ }^{16}$

** Self-reported or abstracted from early records.

$\mathrm{FEV}_{1}$, forced expiratory volume in $1 \mathrm{~s}$; LRTls, lower respiratory tract infections; URTIs, upper respiratory tract infections, excluding colds.

provide robust $\mathrm{p}$ values and confidence intervals (CI). Potential interactions between significant variables in the adjusted model were examined within the linear regression models.

To estimate indirect pathways present within the adjusted model (ie, non-independent predictors of $\mathrm{FEV}_{1}$, which are mediated through other variables), it was reconstructed as a path diagram. In order to allow comparison between variables, and estimate relative importance, standardised beta coefficients $(\beta)$ were derived for each explanatory variable (where a standardised coefficient is the SD change in $\mathrm{FEV}_{1}$ elicited by $1 \mathrm{SD}$ increase in an explanatory variable). Estimates, $\mathrm{p}$ values and confidence intervals were obtained by Monte-Carlo bootstrapping (50 000 repeats) of the maximum likelihood estimates.

All standard statistical analyses were performed using Stata 9.2 (StataCorp, College Station, USA), while AMOS 7.0 (SPSS Inc, Chicago, Illinois, USA) was used for the path analysis.

\section{RESULTS}

Of the original 1142 study members, 832 (89\% of the surviving sample of 932 children whose families remained in Newcastle upon Tyne for at least the first year of the study) were traced at age $49-51$ years. ${ }^{17}$ Of these, 574 completed the health and lifestyle questionnaire, 412 attended the clinical examination and 403 provided usable $\mathrm{FEV}_{1}$ values, which after excluding 11 twins left a sample of 392 . The study sample did not differ significantly $(p>0.05)$ from the members of the original cohort not included in this analysis in terms of any of the factors around birth, infancy and childhood except for sex (women were more likely to attend the clinical examination then men; $\mathrm{p}<0.001)$.

Descriptive statistics for all variables are shown in tables 1 and 2 and the results of the regression analysis (including crude and adjusted regression coefficients) are shown in table 3. Male sex and greater height were significantly associated with higher $\mathrm{FEV}_{1}(\mathrm{p}<0.001)$. Although a substantial portion of the impact of sex was mediated through height $(p<0.001)$, the associations were independent of each other. A prior diagnosis of asthma was associated with significantly lower adult $\mathrm{FEV}_{1}$, both at the univariate level $(p=0.006)$ and after adjustment for other significant variables $(p=0.013)$.

\section{Fetal, infancy and childhood factors}

More disadvantaged social class at birth was a significant unadjusted predictor of reduced $\mathrm{FEV}_{1}(p=0.031)$. However, after adjustment for adult smoking status and body fat percentage, it was no longer significant $(p=0.263)$. While standardised birth weight was not a significant univariate predictor of adult $\mathrm{FEV}_{1}$, it became significant after adjustment for sex and remained so in the fully adjusted model $(p=0.011)$.

Of the childhood illness variables, only the number of LRTIs (between the ages of 0 and 5 years) showed a significant association with $\mathrm{FEV}_{1}(p=0.021)$, which remained in the adjusted model. As a continuous variable, duration of breastfeeding showed no association with adult $\mathrm{FEV}_{1}(p=0.615)$. However, when dichotomised at 4 weeks, individuals breastfed for less than 4 weeks had a significantly lower adult $\mathrm{FEV}_{1}$ $(p=0.005)$ that was not substantially altered in the adjusted model $(p=0.017)$.

\section{Adult factors}

Current smokers had substantially lower $\mathrm{FEV}_{1}$ values than never smokers (adjusted $p<0.001$ ). An inverse association was seen between per cent body fat and $\mathrm{FEV}_{1}(\mathrm{p}<0.001)$ and remained in the adjusted model $(p=0.010)$. While physical activity, occupation, self-reported LRTIs within the past 3 years and alcohol consumption were significant at the univariate level, they were not in the adjusted model. The associations of $\mathrm{FEV}_{1}$ with each of occupational exposure and alcohol consumption were explained by the sex differences in their distributions (men were more likely to be employed in "increased" exposure jobs, and more likely to drink larger quantities of alcohol) and $\mathrm{FEV}_{1}$. The significant univariate association with self-reported LRTIs within the past 3 years was lost after adjustment for asthma and cigarette smoking status. Rather than being accounted for by any one factor, the association between physical activity and $\mathrm{FEV}_{1}$ was reduced only after simultaneous adjustment for sex, cigarette smoking and body fat.

\section{Relative importance}

Figure 1 illustrates the adjusted model in schematic form, as estimated by path analysis. The standardised direct effect of each significant relationship is shown, as well as the standardised total effect of each variable (ie, including both the direct effect and indirect effects mediated through other variables). Sex, which is both directly predictive of $\mathrm{FEV}_{1}$ and indirectly associated through height, birth weight and body fat percentage, had the highest total effect ( $\beta=-0.626$ (95\% CI -0.683 to $-0.563)$ ) while the effect of height was less than half the size $(\beta=0.263$ (95\% CI 0.159 to 0.365$)$ ); however, conceptually, this should be combined with the value for height squared ( $\beta=0.094$ (95\% CI 0.021 to 0.165$)$ ).

After sex and height, current smoking was the next largest predictor of adult $\mathrm{FEV}_{1}(\beta=-0.178$ (95\% CI -0.256 to $-0.100)$ ). The predictive total effects of birth weight and the number of childhood LRTIs were $\beta=0.150$ (95\% CI 0.076 to 0.223 ) and $\beta=-0.121$ ( $95 \%$ CI -0.195 to -0.047 ), respectively, 
Figure 1 Path diagram of the adjusted regression model, showing predictors of forced expiratory volume in $1 \mathrm{~s}\left(\mathrm{FEV}_{1}\right)$. Direct effects are represented by solid arrows and are labelled with standardised coefficients $(\beta)$. Intermediate associations between independent variables are represented by broken arrows, with the arrow direction indicating the hypothesised direction of causal flow. Indirect effects are any pathways that are mediated through at least one intermediate (eg, sex, body fat, $\mathrm{FEV}_{1}$ ). The standardised total effect for each variable is the sum of the direct and indirect effects, and the value is shown underneath the variable name. Error terms, covariance between error terms and relationships with height squared are omitted for simplicity.

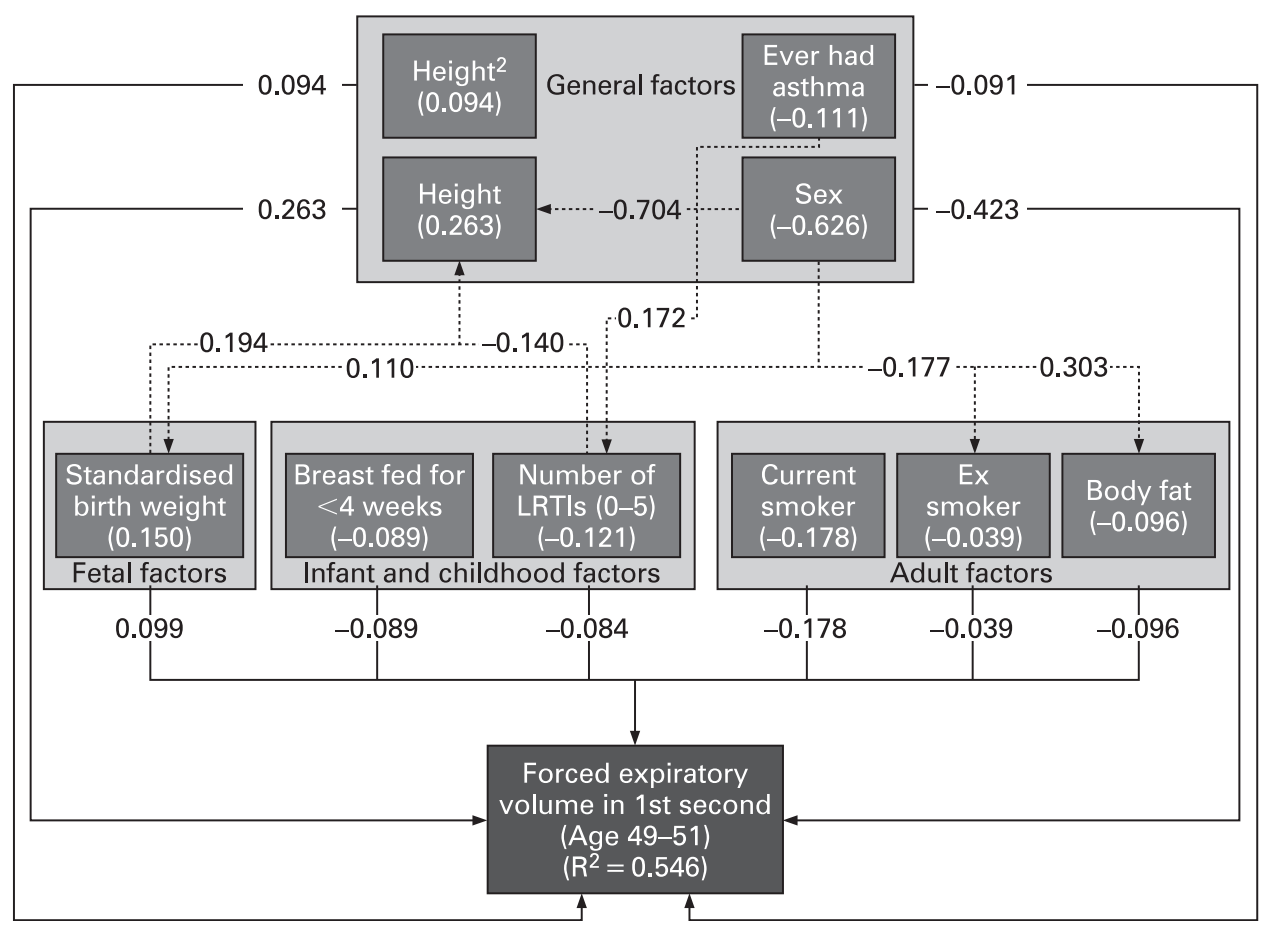

although in both cases nearly a third of the effect was mediated through achieved adult height. The impacts of asthma $(\beta=-0.111(95 \%$ CI -0.184 to -0.039$))$, per cent body fat $(\beta=-0.096(95 \%$ CI -0.172 to -0.019$))$ and duration of breast feeding ( $\beta=0.089$ ( $95 \%$ CI -0.162 to -0.018$)$ ) were of similar magnitude.

\section{Interactions}

No significant interactions were observed between sex and any other variable in the adjusted model. Of all other potential interactions, only birth weight and current smoking status were shown to be significantly interacting $(p=0.001)$, with birth weight showing a greater association with $\mathrm{FEV}_{1}$ among current smokers compared with never smokers.

\section{DISCUSSION \\ Principle findings}

We have investigated lifecourse predictors of adult respiratory health using data from the Newcastle Thousand Families Study. Sex, adult height, per cent body fat, history of asthma, current cigarette smoking status, standardised birth weight, history of childhood LRTIs and a short (less than 4 weeks) duration of breast feeding were all shown to be independently associated with $\mathrm{FEV}_{1}$. Several indirect pathways, including these variables, were also identified, suggesting that some of their effects may be mediated through factors later in the lifecourse.

\section{Strengths and weaknesses}

The main strength of this study is that we were able to analyse data collected prospectively on early life experience alongside current indices of adult health and lifestyle. Unusually for this type of study, detailed and prospectively collected data were available on socioeconomic circumstances, infections and feeding in early life. Measurements at age 49-51 years included a direct estimate of per cent body fat based on bioelectrical impedance which, in contrast with body mass index, is largely independent of build.
Of 1142 people recruited at birth in 1947, 34\% participated in this study, a favourable inclusion rate compared with similar longitudinal studies. ${ }^{818}$ Apart from sex, the study sample was comparable for all early life variables included in this study. Given that no interactions were observed between sex and any other significant variable, we can be confident that this did not bias the overall results. In addition, the inclusion of cohort members who had moved out of the study region increased the representativeness of the population studied. Unfortunately, the lack of modern reference values for $\mathrm{FEV}_{1}$ for a typical general population (ie, one that contains patients with asthma and smokers), makes it difficult to compare this cohort to the general population in terms of respiratory function.

To account for possible occupation exposures, a job exposure matrix was used to estimate exposure to asbestos, dust and fumes from retrospectively reported job titles. Data on the duration of employment in at risk jobs and details of the specific duties were not available. In combination with potential recall bias, it is unlikely that the occupational variable had sufficient power to detect any direct associations, but it is also unlikely to have confounded any of our results.

The use of path analysis imparts several benefits over standard linear regression, including a more illustrative quantification of the different pathways of influence. There are, however, certain limitations of the procedure that are important to note. Firstly, the direction of causal flow has to be inferred by the researcher. This should be less of an issue in this study, however, as the direction was usually indicated by the temporal relationships between the variables.

As with all forms of statistical modelling, path models are also susceptible to the nuances of the data from which they are constructed. It is therefore important to consider the characteristics of the cohort studied when estimating the relevance to other populations. ${ }^{17}$

A more specific limitation of path analysis is the sensitivity to error. Since effect sizes are estimated from standardised coefficients, and standardised coefficients are influenced by 
standard deviations, then any source of error has a potential impact on the relative effect size. However, given that the majority of data included in this study were prospectively collected, then this issue is likely to be as small as is possible for this type of investigation.

\section{Comparisons with other studies}

Sex and height have long been known to dictate a large proportion of the natural variation in lung function, and are hence standard variables in prediction equations. ${ }^{19} 20$ More recently, it has been suggested that body fat should also be factored into these equations. ${ }^{21}$ Our results confirm that body composition is predictive of adult $\mathrm{FEV}_{1}$, although the effect was reduced substantially after adjustment for other factors.

The identified association between standardised birth weight and adult lung function provides further support for the "fetal programming" hypothesis, ${ }^{22}$ with partial mediation via adult height. The results of previous studies have been inconsistent, with a meta-analysis suggesting a small positive association. ${ }^{2}$ Our results cannot be directly compared with this metaanalysis, since a standardised index of birth weight was used. However, when we substituted crude birth weight into the adjusted model, a coefficient of 0.134 (95\% CI 0.024, 0.245) was observed. Although this value is greater in magnitude than the meta-estimate $(0.048$ (95\% CI 0.026, 0.070)), the two values are not significantly different $(p=0.137)$. Nevertheless, it is important to note that the Thousand Families cohort was born when food rationing was still commonplace throughout the UK. It has been proposed that, during this time, the normal nutritional variation between UK social groups was attenuated. ${ }^{23}$ This hypothesis appears to be supported by the lack of a socioeconomic gradient for birth weight in the Thousand Families cohort. ${ }^{24}$

In common with previous research, ${ }^{3-8}$ this study demonstrated a direct linear association between increasing number of

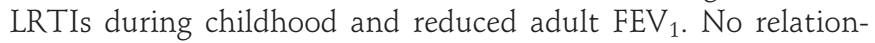
ship was observed between birth weight and childhood LRTIs, although some of the effect of LRTIs was mediated through achieved adult height. Unfortunately, this study does not help to clarify the direction of causality between childhood LRTIs and $\mathrm{FEV}_{1}$. Indeed, early lung infections may simply be more likely in individuals with pre-existing respiratory problems.

In common with other studies., ${ }^{25}{ }^{26}$ we identified a clear negative association between asthma and $\mathrm{FEV}_{1}$. However, historically, childhood asthma was often diagnosed as "wheezy bronchitis", ${ }^{27}$ hence it is possible that under ascertainment has occurred. Neither whooping cough nor tuberculosis was associated with adult $\mathrm{FEV}_{1}$. In the case of tuberculosis, this may have been due to low power. However, for whooping cough this is less likely to be the case, as $44 \%$ of the participants were diagnosed with whooping cough before the age of 5 years. Consistent with previous findings, ${ }^{4-6} 28$ childhood whooping cough does not appear to have a long term impact on adult respiratory function

The impact of breast feeding on long term respiratory health has received relatively little attention. Although several studies have demonstrated better respiratory outcomes among children who have been breast fed, ${ }^{29}{ }^{30}$ very few have investigated whether this trend continues into adulthood. One Canadian study of adults aged between 35 and 79 years identified a lower $\mathrm{FEV}_{1}$ (albeit non-significantly) among those that had not been breast fed. ${ }^{31}$ A more recent study found that $\mathrm{FEV}_{1}$ was nonsignificantly lower among the individuals who had been breast fed for less than 4 weeks. ${ }^{32}$ We found a similar trend, although in our data the effect was substantially larger (and statistically significant). However, no linear association was observed between the duration of breast feeding as a continuous variable and $\mathrm{FEV}_{1}$. Further research is clearly required to explore the nature of this relationship.

In contrast with our findings, socioeconomic status and physical activity have both previously been associated with $\mathrm{FEV}_{1}{ }^{33}{ }^{34}$ This is potentially because of covariance with other factors, including body fat and cigarette smoking status. However, it is also possible that statistical power may have been an issue because of the low number of study members from the more advantaged childhood socioeconomic groups and the relatively small number of moderate and highly active individuals.

\section{CONCLUSION}

Our study confirms that adult lung function is determined by a number of factors, acting both directly and indirectly throughout the lifecourse. Birth weight (standardised for sex and gestational age) and childhood LRTIs were both predictive of adult $\mathrm{FEV}_{1}$. Despite the various significant effects reported, it is important to note that current smoking was the strongest individual predictor of adult $\mathrm{FEV}_{1}$ after sex and height. Therefore, prevention and cessation of cigarette smoking should still be considered the primary intervention for improving respiratory health at a population level.

Acknowledgements: We thank the Thousand Family Study members for taking part and the study teams past and present. We also thank Professor David Coggon for supplying the Job Exposure Matrix and advising on its use.

Funding: This analysis was funded by the Newcastle Healthcare Charity.

Competing interests: None.

Ethics approval: Ethics approval for the study was obtained from the appropriate local research ethics committees.

\section{REFERENCES}

1. Barker DJ. The developmental origins of adult disease. Eur J Epidemiol 2003;18:733-6.

2. Lawlor DA, Ebrahim S, Davey Smith G. Association of birth weight with adult lung function: findings from the British Women's Heart and Health Study and a metaanalysis. Thorax 2005;60:851-8.

3. Shaheen SO, Barker DJ, Holgate ST. Do lower respiratory tract infections in early childhood cause chronic obstructive pulmonary disease? Am J Respir Crit Care Med 1995;151:1649-51.

4. Shaheen S0, Barker DJ, Shiell AW, et al. The relationship between pneumonia in early childhood and impaired lung function in late adult life. Am J Respir Crit Care Med 1994:149:616-19.

5. Shaheen So, Sterne JAC, Tucker JS, et al. Birth weight, childhood lower respiratory tract infection, and adult lung function. Thorax 1998;53:549-53.

6. Johnston IDA, Strachan DP, Anderson HR. Effect of pneumonia and whooping cough in childhood on adult lung function. N Engl J Med 1998;338:581-7.

7. Burchfiel CM. Factors associated with variations in pulmonary function among elderly Japanese-American men. Chest 1997;112:87-97.

8. Barker DJ, Godfrey KM, Fall C, et al. Relation of birth weight and childhood respiratory infection to adult lung function and death from chronic obstructive airways disease. BMJ 1991;303:671-5

9. Edwards CA, Osman LM, Godden DJ, et al. Relationship between birth weight and adult lung function: controlling for maternal factors. Thorax 2003:58:1061-5.

10. Lamont D, Parker L, White M, et al. Risk of cardiovascular disease measured by carotid intima-media thickness at age 49-51: lifecourse study. BMJ 2000;320:273-8.

11. Pearce MS, Birrell FN, Francis RM, et al. Lifecourse study of bone health at age 4951 years: the Newcastle thousand families cohort study. J Epidemiol Community Health 2005:59:475-80.

12. Pearce MS, Unwin NC, Parker $L$, et al. Life course determinants of insulin secretion and sensitivity at age 50 years: the Newcastle Thousand Families Study. Diabetes Metab Res Rev 2005;22:118-25.

13. Leon DA, Lithell HO, Vagero D, et al. Reduced fetal growth rate and increased risk of death from ischaemic heart disease: cohort study of 15000 Swedish men and women born 1915-29. BMJ 1998;317:241-5.

14. Kuh DJ, Cooper C. Physical activity at 36 years: patterns and childhood predictors in a longitudinal study. J Epidemiol Community Health 1992:46:114-19. 
15. Pearce MS, Hayes L, on behalf of the Newcastle Heart Project and the Newcastle Thousand Families Study. Self-reported smoking status and exhaled carbon monoxide: results from two population-based epidemiologic studies in the north of England. Chest 2005;128:1233-8.

16. Pannett B, Coggon D, Acheson ED. A job-exposure matrix for use in population based studies in England and Wales. Br J Ind Med 1985;42:777-83.

17. Lamont DW, Parker L, Cohen MA, et al. Early life and later determinants of adult disease: a 50 year follow-up study of the Newcastle Thousand Families cohort. Public Health 1998;112:85-93.

18. Lopuhaa CE, Roseboom TJ, Osmond C, et al. Atopy, lung function, and obstructive airways disease after prenatal exposure to famine. Thorax 2000;55:555-61.

19. Quanjer PH. Standardised lung function testing of the European Community for Coal and Steel. Bull Eur Physiopathol Respir 1983;19:7-10.

20. Falaschetti E, Laiho J, Primatesta P, et al. Prediction equations for normal and low lung function from the Health Survey for England. Eur Respir J 2004:23:456-63.

21. Cotes JE, Chinn DJ, Reed JW. Body mass, fat percentage, and fat free mass as reference variables for lung function: effects on terms for age and sex. BMJ 2001:56:839.

22. Godfrey KM, Barker DJ. Fetal programming and adult health. Public Health Nutr 2001:4:611-24.

23. Addison $\mathbf{P}$. The impact of the Second World War. In: Addison $\mathrm{P}$, Jones $\mathrm{H}$, eds. A companion to contemporary Britain, 1939-2000. Oxford: Blackwell Publishing, 2007:8.
24. Pearce MS, Deary IJ, Young AH, et al. Growth in early life and childhood $\mathrm{IO}$ at age 11 years: the Newcastle Thousand Families Study. Int J Epidemiol 2005;34:673-7.

25. Oswald H, Phelan PD, Lanigan A, et al. Childhood asthma and lung function in midadult life. Pediatr Pulmonol 1997;23:14-20.

26. Godden DJ, Ross S, Abdalla M, et al. Outcome of wheeze in childhood. Symptoms and pulmonary function 25 years later. Am J Respir Crit Care Med 1994;149:106-12

27. Williams $\mathbf{H}$, McNicol KN. Prevalence, natural history, and relationship of wheezy bronchitis and asthma in children. An epidemiological study. Br Med J 1969;4:321-5

28. Britten N, Wadsworth J. Long term respiratory sequelae of whooping cough in a nationally representative sample. Br Med J (Clin Res Ed) 1986:292:441-4.

29. Cushing $\mathbf{A H}$, Samet JM, Lambert WE, et al. Breastfeeding reduces risk of respiratory illness in infants. Am J Epidemiol 1998;147:863-70.

30. Oddy WH, Sly PD, de Klerk NH, et al. Breast feeding and respiratory morbidity in infancy: a birth cohort study. Arch Dis Child 2003;88:224-8

31. Shaukat A, Freudenheim JL, Grant BJB, et al. Is being breastfed as an infant associated with adult pulmonary function? J Am Coll Nutr 2005;24:327-33.

32. Rudnicka AR, Owen CG, Strachan DP. The effect of breastfeeding on cardiorespiratory risk factors in adult life. Pediatrics 2007:119:e1107-15.

33. Hegewald MJ, Crapo RO. Socioeconomic status and lung function. Chest 2007:132:1608-14.

34. Lawlor DA, Ebrahim S, Davey Smith G. Association between self-reported childhood socioeconomic position and adult lung function: findings from the British Women's Heart and Health Study. Thorax 2004;59:199-203.

\section{BMJ Masterclasses}

BMJ Masterclasses are educational meetings designed specifically to meet the learning needs of doctors. They help doctors keep up to date with the latest evidence and recent guidelines in major clinical areas, enabling them to use the latest evidence to make better decisions. The latest evidence, recent guidelines and best practice are delivered in an interactive and informative manner by leading experts. The speakers are specifically chosen as highly-skilled communicators who can authoritatively enthuse the audience and interpret the latest research and guidelines into practical tips for busy doctors. BMJ Masterclasses have proved a huge hit with clinicians, with many saying they have influenced their clinical practice.

http://masterclasses.bmj.com/ 